\title{
Extraction and characterization of collagen from Antarctic and Sub-Antarctic squid and its potential application in hybrid scaffolds for tissue engineering
}

\author{
Rui C.G. Coelho ${ }^{\mathrm{a}, \mathrm{b}}$, Ana L.P. Marques ${ }^{\mathrm{a}, \mathrm{b}}$, Sara M. Oliveira ${ }^{\mathrm{a}, \mathrm{b}}$, Gabriela S. Diogo ${ }^{\mathrm{a}, \mathrm{b}}$, Rogério P. Pirraco ${ }^{\mathrm{a}, \mathrm{b}}$, \\ Joana Moreira-Silva ${ }^{\mathrm{a}, \mathrm{b}}$, José C. Xavier ${ }^{\mathrm{c}, \mathrm{d}}$, Rui L. Reis ${ }^{\mathrm{a}, \mathrm{b}}$, Tiago H. Silva ${ }^{\mathrm{a}, \mathrm{b}, *}$, João F. Mano ${ }^{\mathrm{a}, \mathrm{b}, \mathrm{e}}$
}

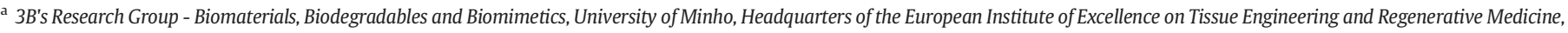 \\ AvePark - Parque de Ciência e Tecnologia, 4805-017 Barco - Guimarães, Portugal \\ ${ }^{\mathrm{b}}$ ICVS/3B's - PT Government Associate Laboratory, Braga/Guimarães, Portugal \\ ${ }^{c}$ Marine and Environmental Sciences Centre (MARE), Department of Life Sciences, University of Coimbra, 3004-517 Coimbra, Portugal \\ d British Antarctic Survey, Natural Environment Research Council, High Cross, Madingley Road, Cambridge CB3 OET, United Kingdom \\ e CICECO, Department of Chemistry, University of Aveiro, 3810-193 Aveiro, Portugal
}

\section{A R T I C L E I N F O}

\section{Article history:}

Received 19 November 2016

Received in revised form 7 April 2017

Accepted 9 April 2017

Available online 21 April 2017

\section{Keywords:}

Squid collagen

Antarctic

Three dimensional hybrid scaffolds

3D printing

Marine biomaterials

Hierarchical scaffolds

\begin{abstract}
A B S T R A C T
Collagen is the most abundant protein found in mammals and it exhibits a low immunogenicity, high biocompatibility and biodegradability when compared with others natural polymers. For this reason, it has been explored for the development of biologically instructive biomaterials with applications for tissue substitution and regeneration. Marine origin collagen has been pursued as an alternative to the more common bovine and porcine origins. This study focused on squid (Teuthoidea: Cephalopoda), particularly the Antarctic squid Kondakovia longimana and the Sub-Antarctic squid Illex argentinus as potential collagen sources. In this study, collagen has been isolated from the skins of the squids using acid-based and pepsin-based protocols, with the higher yield being obtained from $I$. argentinus in the presence of pepsin. The produced collagen has been characterized in terms of physicochemical properties, evidencing an amino acid profile similar to the one of calf collagen, but exhibiting a less preserved structure, with hydrolyzed portions and a lower melting temperature. Pepsin-soluble collagen isolated from I. argentinus was selected for further evaluation of biomedical potential, exploring its incorporation on poly- $\varepsilon$-caprolactone (PCL) 3D printed scaffolds for the development of hybrid scaffolds for tissue engineering, exhibiting hierarchical features. (c) 2017 Elsevier B.V. All rights reserved.
\end{abstract}

\section{Introduction}

Natural materials are the focus of extensive research on their application in different areas addressing human well-being, from food sector to cosmetics and medical field, increasing the pressure over natural resources. This is calling the attention of scientists and engineers towards the development of more sustainable processes and the recent exploitation of marine organisms is much more oriented within a circular economy context, in which valorization of byproducts gains a pivotal role [1,2]. Additionally, the Antarctic resources initially studied within the ideal of an unexplored zone of globe devoted to science and peace, are being now the subject for evaluation of valorization strategies with a clear sustainability pattern [3,4]. Indeed, various Parties of the

\footnotetext{
* Corresponding author at: 3B's Research Group - Biomaterials, Biodegradables and Biomimetics, University of Minho, AvePark - Parque de Ciência e Tecnologia, Zona Industrial da Gandra, 4805-017 Barco - Guimarães, Portugal.

E-mail address: tiago.silva@dep.uminho.pt (T.H. Silva).
}

Antarctic Treaty have regularly proposed to assess regulations on bioprospecting in the Antarctic (see www.ats.aq). One of such strategies addresses the isolation of compounds with high added value, to enter the value chain abovementioned, in which collagen has a golden status, due to its favorable properties of non-toxicity, low immunogenicity, biodegradability and biocompatibility [5-8].

Collagen is inserted in the family of fibrous proteins present in multicellular animals and is the most abundant protein in mammals. The main function of collagen is focused on the support and maintenance of structural integrity, providing texture, shape and resilience, and it is also known for having a regulatory role in tissue development $[9,10]$. About $25 \%$ of the human body is composed by this protein, being identified up to today at least 28 genetically different types of collagen, classified based on their organization and supramolecular structures function and distribution in tissues [11-13]. Actually, an epidermal collagen type XXIX has been proposed [14], but the coding gene COL29A1 seems to be identical to COL6A5 and thus its acceptance is under debate [15]. Within marine resources, collagen is commonly isolated from fish skins $[16,17]$ or jellyfish [18], but other sources have 
been also explored, such as sea sponges [19,20], echinoderms [21] and cephalopods [22]. Within this latter group of animals, squids as source of collagen are still poorly explored, but arise as an elegant model for valorization of marine resources in the Antarctic/sub-Antarctic regions due to recent studies on the ecology of squid species from this region of the Globe [23]. Indeed, there are squid species, as Kondakovia longimana distributed in Antarctic and sub-Antarctic waters [24], and Illex argentinus distributed in sub-Antarctic waters [23,25], allowing a direct comparison between materials obtained from organisms from neighbor regions. Moreover, the latter squid species is largely explored for food purposes [26] and the production of collagen from its skins would represent an attractive way for valorization of by-products.

Collagen is usually obtained at a very low yield through the traditional process, based in acid treatment with organic acids, rendering the designated acid soluble collagen (ASC). However, it is possible to increase the extraction yield with the use of pepsin, which acts on the edge of the polypeptide chains, cutting telopeptides and thus facilitating their solubilization in acidic solutions, with the resulting collagen being denoted as pepsin soluble collagen (PSC) [27].

Considering its favorable features and the central role that collagen assumes in extracellular matrix, it has been widely proposed for biomedical application, namely the types I to $\mathrm{V}[28,29]$, with marine origin collagen being consistent with collagen type I (fish skins, scales and bones), type II (jellyfish, fish cartilage) or type IV (sea sponges) [27]. In particular, the use of collagen on the development of biomaterials mimicking extracellular matrix in tissue engineering approaches is a hot topic [30-32]. Collagen scaffolds normally exhibit excellent biocompatibility and tuning of cellular behavior, but lack adequate mechanical properties, from which the combination with synthetic polymers has been proposed [33]. One of the more elegant ways to achieve that combination of enhanced features is the design of hybrid scaffolds, as a way of producing multiscale structures for tissue engineering [34,35]. In this context, the use of 3D printing technology has gained increasing prominence, with the production of an oriented fibrillar structure further modified to achieve a hierarchical architecture [36]. Such modification is intended to affect porosity, surface chemistry and roughness of the scaffolds, together with an increase of cell anchorage points aiming to increase cell seeding efficiency and enhance the performance of the resultant construct [37-39].

In this work, collagen has been extracted from $K$. longimana and from I. argentinus and characterized by Fourier transform infrared spectroscopy (FTIR) and amino acid analysis to assess their chemical features, sodium dodecyl sulfate polyacrylamide gel electrophoresis (SDSPAGE) to address their purity and identify collagen type and differential scanning calorimetry (DSC) to evaluate melting temperature. Selected collagen samples have been further incorporated into 3D printed poly$\varepsilon$-caprolactone (PCL) scaffolds, with evaluation of morphological and mechanical properties, stability in aqueous media and in vitro compatibility with L929 cells.

\section{Material and methodologies}

\subsection{Materials}

Individuals from $K$. longimana squid species were collected in the Antarctic (Scotia Sea) during an expedition of the British Antarctic Survey in 2013 and kept frozen at $-20^{\circ} \mathrm{C}$. After thawing, skins and muscle were separated and used as raw material for collagen isolation. Skins from $I$. argentinus squid species, captured from the Patagonian shelf (sub-Antarctic waters), resulting from processing of squids for food products were kindly provided by Dr. Julio Maroto (Fundación CETMAR, Vigo, Spain). Poly- $\varepsilon$-caprolactone (with $\mathrm{M}_{\mathrm{w}} 70,000$ to 90,000 ), was purchased to Sigma-Aldrich. All other reagents were of analytical grade and used as received.

\subsection{Extraction of ASC and PSC from K. longimana and I. argentinus squids} biomass

Collagen was extracted from squid materials according to a methodology adapted from $[22,40]$. All processes were carried out at $4{ }^{\circ} \mathrm{C}$. Squid skins and muscles were soaked in $0.1 \mathrm{M} \mathrm{NaOH}$ (VWR International) solution for $6 \mathrm{~h}$ (changed every $2 \mathrm{~h}$ ), with magnetic stirring, to remove non-collagenous proteins. When using skins, pigments were removed by treatment with $1 \% \mathrm{H}_{2} \mathrm{O}_{2}$ solution for $12 \mathrm{~h}$. Skins and muscles were then washed abundantly with distilled water to obtain a pH close to neutral and further soaked in $0.5 \mathrm{M}$ acetic acid (VWR International) solution, for $72 \mathrm{~h}$ with magnetic stirring. The mixture was centrifuged at $9000 \mathrm{~g}$ for $25 \mathrm{~min}$ and the supernatant (with ASC) was collected and kept at $4{ }^{\circ} \mathrm{C}$. The precipitate was re-extracted in $0.5 \mathrm{M}$ acetic acid solution with $3.3 \mathrm{mg}$ of pepsin A (Sigma-Aldrich) per gram of raw material, during $72 \mathrm{~h}$, with magnetic stirring, followed by centrifugation at $9000 \mathrm{~g}$ for $25 \mathrm{~min}$. The supernatant (with PSC) was collected and kept at $4{ }^{\circ} \mathrm{C}$. The ASC and PSC were further dialyzed against $0.1 \mathrm{M}$ acetic acid solution for $12 \mathrm{~h}$, with solution changed every $2 \mathrm{~h}$, frozen at $-80^{\circ} \mathrm{C}$ and freezedried.

The extraction of collagen was performed in triplicate for each squid material for assessment of reproducibility regarding the extraction yield.

\subsection{Fourier transform infrared (FTIR) spectroscopy}

The infrared spectra of collagen samples were obtained in $\mathrm{KBr}$ pellets using a Shimadzu- IR Prestige 21 spectrometer in the spectral region of $4000-800 \mathrm{~cm}^{-1}$ with resolution of $2 \mathrm{~cm}^{-1}$ and taking the average of 32 scans.

\subsection{Differential scanning calorimetry (DSC) analysis}

Thermal profiles of ASC and PSC samples were assessed by DSC (Q100 Thermal Analysis), from 0 to $80^{\circ} \mathrm{C}$, at a heating rate of $1{ }^{\circ} \mathrm{C} \mathrm{min}-1$ to assess melting temperature. An empty capsule was used as reference and the presented values are an average of three independent measures. Values of melting temperature were determined as the average of three independent measurements for each sample.

\subsection{Amino acid analysis}

Amino acid analysis was performed at Centro de Investigaciones Biológicas of the Spanish National Research Council (CSIC), in Madrid (Spain). Collagen samples were firstly completely hydrolyzed and further separated using an ion exchange column. After post-column derivatization by ninhydrin, the samples were analyzed at two wavelengths (440 and $570 \mathrm{~nm}$ ), using a Biochrome 30 (Biochrome Ltd., Cambridge, U.K.). An internal standard of norleucine was used for quantitative analysis. Three independent measurements for each sample were made for the quantification of the average amino acid contents.

\subsection{Sodium-dodecyl-sulfate polyacrylamide gel electrophoresis (SDS-PAGE)}

SDS-PAGE was performed using a 7.5\% separating acrylamide gel and a 3\% stacking acrylamide gel, with a voltage of $60 \mathrm{~V}$ for $20 \mathrm{~min}$ and for an hour with a constant voltage of $144 \mathrm{~V}$. The samples were applied into the wells and electrophoresed in Bio-Rad Miniprotean 3 cell vertical electrophoresis tank. Protein bands were stained for $35 \mathrm{~min}$ with staining solution (0.1\% Comassie Brilliant Blue R-250, from BioRad) and distained with two distaining solutions (containing distilled water, methanol and acetic acid). 


\subsection{Fabrication of PCL scaffolds and production of PCL/collagen scaffolds}

Poly- $\varepsilon$-caprolactone (PCL) granules were inserted in the $3 \mathrm{D}$ Bioplotter ${ }^{\mathrm{TM}}$ (Envisiontec 4th Generation equipment) cartridge and heated up to $90{ }^{\circ} \mathrm{C}$. PCL was printed using an $18 \mathrm{G}$ needle with a strand distance of $1.4 \mathrm{~mm}$, with struts aligned by $90^{\circ}$ in 8 consecutive layers. Scaffolds were cut into pieces with squared $0.50 \times 0.50 \mathrm{~cm}$ base.

I. argentinus PSC was re-solubilized in $0.5 \mathrm{M}$ acetic acid solution (ratio $1: 10 \mathrm{w} / \mathrm{v}$ ) overnight under stirring, at $4{ }^{\circ} \mathrm{C}$. Then collagen was crosslinked with genipin (10 mM) (Commercial Rafer, S.L.), at $37{ }^{\circ} \mathrm{C}$, under stirring, during 5-6 h until collagen solution became light blue.

PCL scaffolds were modified by immersion in $10 \%$ ethylenediamine (Sigma-Aldrich) in 2-propanol (VWR International) during $1 \mathrm{~h}$, at $37^{\circ} \mathrm{C}$, to render less hydrophobic materials, followed by washing with ultra-pure water. Modified 3D PCL scaffolds were then immersed in $0.5 \%$ or $1 \%$ collagen solution during $10 \mathrm{~min}$, after which the resulting systems were frozen at $-80{ }^{\circ} \mathrm{C}$ overnight and freeze-dried.

\subsection{Scanning electron microscopy (SEM)}

Scanning electron microscopy was used to examine the fibrillar structure formed by collagen inside the PCL scaffolds. The PCL/collagen scaffolds were fixed to an adhesive carbon stub and covered with gold using a sputter coater (Cressington 108 Auto) at $30 \mathrm{~mA}$ for $5 \mathrm{~min}$. SEM images were obtained at different magnifications, using a JEOL JSM-6010LV equipment.

\subsection{Micro computer tomography (micro-CT)}

The inner structure, thickness, pore volume and porosity of the hybrid scaffolds were evaluated by micro-computerized tomography using a Bruker SkyScan 1272 equipment (scanned under a $50 \mathrm{kV}$ source for a complete rotation of $360^{\circ}$ ). The X-ray scans were acquired in highresolution mode ( $7.4 \mu \mathrm{m})$. CT-An Software was used to visualize the 2D $\mathrm{X}$-ray sections images of the scaffolds and CT-Vol to visualize the 3D structure.

\subsection{Mechanical properties}

Mechanical properties of scaffolds were assessed by compression tests using an Instron 5543 universal testing machine and a loading cell of $1 \mathrm{kN}$. Compression testing was carried out until a maximum deformation of $60 \%$. The elastic modulus was determined as the average of the values obtained from the initial linear section of the stress/strain curves of at least 5 samples.

\subsection{Determination of water uptake (swelling tests)}

The degree of swelling of collagen freeze-dried sponges was determined by water uptake upon incubation in PBS, at $37{ }^{\circ} \mathrm{C}$ with gentle agitation. After each time point the sample was removed from the solution, the excess of water removed with filter paper and the water uptake was calculated as the relative difference of the sample final and initial weight. At least three samples per condition were analyzed.

\subsection{Biological performance}

\subsubsection{Samples sterilization}

The PCL scaffolds and PCL/collagen scaffolds to be used for cytotoxicity assays and pilot biological performance tests were sterilized with gamma radiation, at room temperature for $24 \mathrm{~h}$, with a maximum dose of $15 \mathrm{kGy}$ (Cobalt 60).

\subsubsection{Evaluation of scaffolds cytotoxicity}

L929 fibroblasts, a standard cell line for the evaluation of scaffolds cytotoxicity according to ISO guidelines, were expanded in DMEM
(Dulbecco's modified Eagle's medium) supplemented with $10 \%$ fetal bovine serum (Alfagene) and 1\% antibiotic-antimycotic mixture (Alfagene). When confluent, TrypLE Express (ThermoFisher) was used and cells seeded in 48 well culture plates at a density of 30,000 cells/ $0.95 \mathrm{~cm}^{2}$. After $24 \mathrm{~h}$ in culture, the different scaffolds formulations were added to the corresponding wells, after being washed 3 times with sterile PBS. Cell metabolic activity was measured using a 3-(4,5-dimethylthiazol-2-yl)-5-(3 carboxymethoxyphenyl) 2-(4-sulphofenyl)2H-tetrazolium, inner salt (MTS) (VWR International) assay at 1, 2 and 3 days after adding the scaffolds. This assay quantified the metabolic activity of the cells by the reduction of tetrazolium salt reagent to formazan (after $3 \mathrm{~h}$ of incubation at $37^{\circ} \mathrm{C}$ ). Absorbance intensity, directly proportional to the cell metabolic activity, was measured at $492 \mathrm{~nm}$ using a microplate reader (Synergy HT, Bio-Tek). The results are the mean of two independent experiments with $n=3$ for each scaffold formulation per experiment, calculated in relation to control (cells cultured in the bottom of the well - polystyrene - without added materials).

\subsubsection{Live/dead cell assay}

Cell viability and cells distribution through the scaffolds were evaluated by Live/Dead (Calcein (AM)/Propidium iodide (PI) (Alfagene)) assay. L929 cells were seeded onto the different scaffolds (100,000 cell per scaffold); at different time points - 1,2 and 3 days after seeding culture medium was removed and replaced by a dilution of AM (1:1200) and PI (1:300) in culture medium for 30 min at dark. The solution was removed from each well, followed by 3 washes with PBS and immediately visualized by Confocal Laser Scanning Microscopy (CLSM) (TCS SP8, Leica). Live cells were highlighted by green color through a fluorescent filter (fluorescence excitation of $494 \mathrm{~nm}$ and emission of $517 \mathrm{~nm}$ ) after the internalization and hydrolysis of calcein into cells membrane; dead cells were identified by red color through a rhodamine filter (fluorescence excitation of $535 \mathrm{~nm}$ and emission of $617 \mathrm{~nm}$ ), by their binding to DNA.

\subsection{Statistical analysis}

Statistical analysis of data was performed using GraphPad Prism Version 6 . Normality was verified by the Shapiro-Wilk test. Normal distributed data were then analyzed using one-way analysis of variance (ANOVA) with Tukey's post hoc test or two-way ANOVA with Bonferroni post hoc test. When normality was not verified, a nonparametric $t$-test with Welch's correction was performed.

Differences between the groups with a probability value higher than $95 \%(p<0.05)$ were considered to be statistically significant.

\section{Results and discussions}

\subsection{Collagen extraction}

Two squid species were selected as raw-material for the isolation of type I collagen: K. longimana that can reach large sizes ( $>1000 \mathrm{~mm}$ of mantle length (ML)), highly abundant in Antarctic waters [41], and $I$. argentinus, a species very common in sub-Antarctic waters (at the Patagonian shelf; South Atlantic ocean) that can reach up to $350 \mathrm{~mm}$ ML $[23,42]$. Ecologically, these two species are different: K. longimana is from a different family (family Onychoteuthidae) that of I. argentinus (family Ommastephidae), and live generally in different depths: I. argentinus is known to occur seasonally at the Patagonian shelf $(<250 \mathrm{~m}$ deep) and is considered to be a muscular species; on the other hand, although $K$. longimana is known to occur in deeper, colder waters than $I$. argentinus and has been classified as a sinker, there are reports of floating specimens. This is probably due to the high concentration of ammonia in the flesh of $K$. longimana, meaning they are positively buoyant after death [43-46]. 
Table 1

Yields of collagen extractions $(n=3)$.

\begin{tabular}{llll}
\hline Squid species and materials & & Collagen & Yield (mean \pm SD) \\
\hline Kondakovia longimana & Skin & ASC & $0.94 \% \pm 0.07$ \\
& & PSC & $1.18 \% \pm 0.29$ \\
& \multirow{2}{*}{ Muscle } & ASC & $1.05 \% \pm 0.58$ \\
& \multirow{2}{*}{ Skin } & PSC & $0.88 \% \pm 0.11$ \\
& & ASC & $0.81 \% \pm 0.08$ \\
& & PSC & $3.26 \% \pm 0.05$ \\
\hline
\end{tabular}

ASC and PSC were extracted from both skin and muscle of $K$. longimana and from skin of I. argentinus and the yields of extraction were calculated as the ratio of the total weight of extracted collagen and the initial wet weight of squid skin/muscle. The obtained values are depicted in Table 1.

The yields observed from $K$. longimana skin and muscle were quite low, with values around $1 \%$, while from I. argentinus skin more favorable values where achieved, particularly for PSC where a higher $(\mathrm{p}<0.05)$ value of $3.26 \%$ was obtained. This is in agreement with literature, where the yield of collagen extraction from other squid species is proposed to be in the range $3-11 \%$ [47].

Nevertheless, the value is underestimated due to the high water content of the initial biomass (about $3 / 4$ of its mass), but the extraction of collagen from dried skins is not recommended since drying leads to the entrainment of the pigments in the protein matrix, being then coextracted with collagen, thus requiring additional purification steps.

The extracted materials were characterized by FTIR to determine the presence of collagen by the identification of the characteristic bands, namely the peaks associated to amide groups at $1659 \mathrm{~cm}^{-1}$ (amide I), $1555 \mathrm{~cm}^{-1}$ (amide II) and $1240 \mathrm{~cm}^{-1}$ (amide III), as well as a strong signal at $3281 \mathrm{~cm}^{-1}$, corresponding to the stretching of $\mathrm{O}-\mathrm{H}$ bonds [48, 49], pointing out therefore that the integrity and the composition of the polypeptide chains have been kept. FTIR spectra of collagen extracted from both species are illustrated in Fig. 1.

ASC obtained from both skin and muscle of $K$. longimana exhibited spectra similar to type I collagen [48], while the PSC revealed a high content of impurities and probably a significant degradation, with poorly defined bands. By its turn, FTIR spectra of collagen extracted from the skin of $I$. argentinus showed the presence of type I collagen with a high degree of purity, with expected peaks well defined.

Thermal profile of ASC and PSC samples was also analyzed to assess the melting temperature of the collagenous samples. The values presented in Table 2 show a similarity within the ASC and the PSC samples, with the former having values around $24^{\circ} \mathrm{C}$ and the latter around $34{ }^{\circ} \mathrm{C}$.

Lower melting temperatures are commonly associated with a lower content of amino acids proline and hydroxyproline (Ohpro) or with a reduced hydroxylation degree [50-52]. However, the determination of the amino acids profile, indicated in Table 3, revealed a similar content of Ohpro in all samples. The explanation for significantly lower values from ASC when comparing with PSC may thus be related to other factors, namely the moisture of the samples, which would affect melting of samples upon temperature increase [53]. Apparently, the removal of telopeptides by pepsin is leading to more stable samples after freeze-drying, hindering their thermal structural change upon heating. Indeed, not only the intermolecular interactions between collagen molecules play a role on the thermal stability of samples, but also the freeze and thaw of samples [54].

Besides the presence of Ohpro, an amino acid characteristic of collagenous proteins and responsible for maintaining triple helix (secondary collagen structure) [56], the amino acid profile revealed as well the presence of a high amount of glycine (about 1/3 of total residues), consistent with the model for collagen in which in every sequence of 3 amino acids one of them is glycine, observed on other marine origin collagens and on calf collagen taken as reference [55].

The electrophoretic pattern of collagen samples was also examined by SDS-PAGE, to better understand the results obtained by spectroscopy. The image in Fig. 2 illustrates the obtained results and it is possible to verify that only ASC from K. longimana skin and both ASC and PSC from I. argentinus skin contain clearly $\alpha 1, \alpha 2$ and $\beta$ chains, characteristic of type I collagen. In fact, the latter exhibited an intense band at about $150 \mathrm{kDa}$ being attributed to the presence of polypeptide chains equivalent to $\alpha 1(\approx 160 \mathrm{kDa})$ and $\alpha 2(\approx 130 \mathrm{kDa})$ and another band above $250 \mathrm{kDa}$ attributed to $\beta$ chain $(260 \approx \mathrm{kDa})$. PSC from $K$. longimana skin and muscle showed only bands at significantly lower molecular weight, which may indicate that the procedure was not leading to the extraction of collagen, but other compounds, while ASC from $K$.

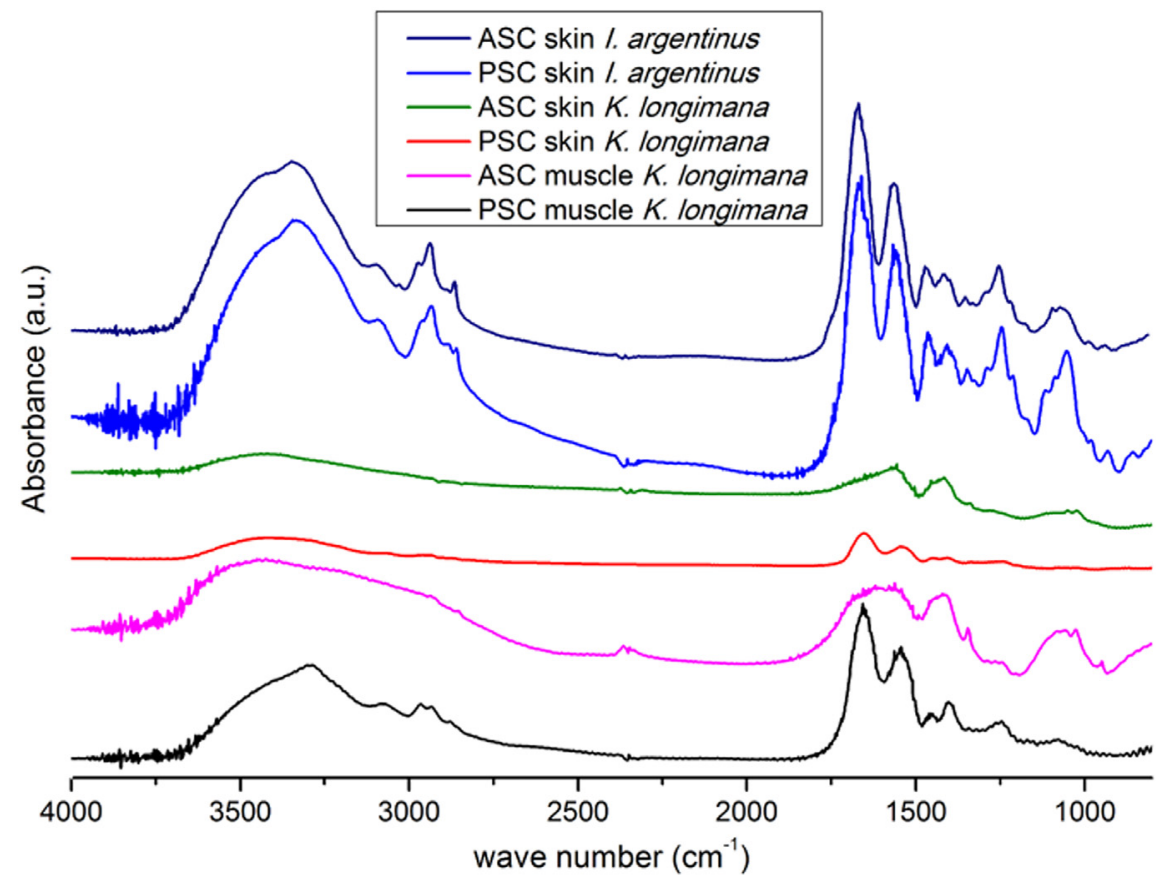

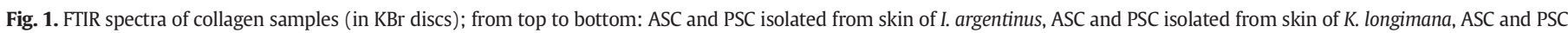
isolated from muscle of $K$. longimana. 
Table 2

Melting temperatures of collagen samples, determined by DSC analysis $(n=3)$.

\begin{tabular}{llll}
\hline \multicolumn{2}{l}{ Squid species and materials } & Collagen & Melting temperature (mean \pm SD) \\
\hline Kondakovia longimana & \multirow{2}{*}{ Skin } & ASC & $24.04{ }^{\circ} \mathrm{C} \pm 0.51$ \\
& & PSC & $34.17{ }^{\circ} \mathrm{C} \pm 0.08$ \\
& Muscle & ASC & $23.75{ }^{\circ} \mathrm{C} \pm 0.01$ \\
& & PSC & $33.74{ }^{\circ} \mathrm{C} \pm 0.35$ \\
Illex argentinus & \multirow{2}{*}{ Skin } & ASC & $23.21^{\circ} \mathrm{C} \pm 0.91$ \\
& & PSC & $31.49{ }^{\circ} \mathrm{C} \pm 0.20$ \\
\hline
\end{tabular}

Table 3

Quantity of amino acids residues present in collagen samples isolated from $K$. longimana skin and muscle and I. argentinus skin (presented values are an average of three independent measurements), comparatively to calf collagen used as reference. * Data from [55].

\begin{tabular}{|c|c|c|c|c|c|c|c|}
\hline \multirow[t]{3}{*}{ AA } & \multirow{2}{*}{\multicolumn{2}{|c|}{$\begin{array}{l}\text { Kondakovia } \\
\text { longimana skin }\end{array}$}} & \multirow{2}{*}{\multicolumn{2}{|c|}{$\begin{array}{l}\begin{array}{l}\text { Kondakovia } \\
\text { longimana } \\
\text { muscle }\end{array} \\
\text { Residues/1000 }\end{array}$}} & \multirow{2}{*}{\multicolumn{2}{|c|}{$\begin{array}{l}\text { Illex argentinus } \\
\text { skin } \\
\text { Residues/1000 }\end{array}$}} & \multirow{3}{*}{$\begin{array}{l}\text { Calf collagen* } \\
\text { Residues/1000 } \\
\text { ASC }\end{array}$} \\
\hline & & & & & & & \\
\hline & ASC & PSC & ASC & PSC & ASC & PSC & \\
\hline Asp & 66 & 77 & 70 & 97 & 71 & 71 & 45 \\
\hline Thr & 18 & 20 & 22 & 29 & 20 & 24 & 18 \\
\hline Ser & 56 & 68 & 61 & 83 & 51 & 59 & 33 \\
\hline Glu & 78 & 86 & 84 & 87 & 82 & 77 & 75 \\
\hline Gly & 303 & 323 & 315 & 278 & 315 & 327 & 330 \\
\hline Ala & 79 & 94 & 81 & 90 & 96 & 97 & 119 \\
\hline Cys & 7 & 4 & 4 & 7 & 5 & 5 & 0 \\
\hline Val & 29 & 26 & 28 & 30 & 26 & 25 & 21 \\
\hline Met & 13 & 22 & 13 & 23 & 22 & 22 & 8 \\
\hline Ile & 12 & 13 & 15 & 18 & 14 & 13 & 11 \\
\hline Leu & 25 & 36 & 31 & 44 & 33 & 33 & 58 \\
\hline Nleu & 102 & 23 & 33 & 16 & 39 & 17 & 37 \\
\hline Tyr & 4 & 4 & 6 & 11 & 4 & 5 & 3 \\
\hline Phe & 12 & 20 & 15 & 29 & 22 & 23 & 14 \\
\hline OHlys & 16 & 19 & 16 & 15 & 20 & 22 & 7 \\
\hline His & 3 & 4 & 5 & 5 & 5 & 6 & 5 \\
\hline Lys & 10 & 14 & 15 & 14 & 16 & 14 & 26 \\
\hline $\operatorname{Arg}$ & 47 & 40 & 49 & 33 & 39 & 38 & 50 \\
\hline Ohpro & 63 & 50 & 63 & 37 & 60 & 62 & 44 \\
\hline Pro & 56 & 55 & 74 & 54 & 59 & 60 & 49 \\
\hline
\end{tabular}

longimana muscle shows the blurred staining normally attributed to degraded or partially hydrolyzed materials [57]. The colder habitat ok $K$. longimana may be related to this behavior, leading to collagen materials more sensible to degradation upon thermal or chemical procedures used during extraction.
From the above results concerning the characterization of the collagen extracts, conjugated with the higher yield of extraction observed on the process to produce PSC from skins of I. argentinus, this material was selected to proceed with the study for evaluation of biomedical potential as component on the development of hybrid scaffolds for cell culture in tissue engineering strategies.

Additionally, marine origin PSC is being recommended for biomedical applications, once telopeptides have been associated with potential immune responses upon in-vivo implantation [58].

\subsection{Production of $P C L /$ collagen hybrid scaffolds}

In order to create hierarchical and hybrid scaffolds, aiming to improve biological performance as 3D cell culture matrix towards tissue regeneration, 3D printed PCL structures were combined with $0.5 \%$ and $1 \%$ collagen (PSC from I. argentinus) solutions. The production of these scaffolds was based on freeze-drying and effectiveness of the crosslinking process, with the rational that the lyophilization process would render microfibrillar structures within the struts composing the original PCL 3D printed scaffolds. These microfibers would create additional places for cell adhesion, benefiting also from the well-known biocompatibility of collagen. Such environment within the more inert PCL structure could bring advantages in a biological point of view, as it can be seen as an attempt to deconstruct relevant cues of the native cellular organization [59].

The 3D printed architectures were characterized by SEM before and after incorporation of collagen and the results depicted in Fig. 3 clearly show the alignment of the PCL filaments produced by bioplotter. The cubic design structure is suitable for the incorporation therein of another material, allowing a good integration between both materials. After incorporation of collagen, it is possible to observe the formation of a spider-web-like collagen microfibrillar structure (Fig. 3B) within the PCL struts, which became much denser when increasing the concentration of collagen solution into $1 \%$, resulting ultimately in a coating (Fig. 3C).

To support the observations made by electron microscopy, the morphological features of the 3D printed and hybrid scaffolds were also characterized by micro-computerized tomography, which allows the collection of three-dimensional information of produced scaffolds, using NRecon software for the 3D reconstruction of the X-rays data see right column in Fig. 3.

The similarity of the density of PCL $\left(1.14 \mathrm{~g} / \mathrm{cm}^{3}\right)$ and collagen (ranges from 0.987 to $1.5 \mathrm{~g} / \mathrm{cm}^{3}$ ) [60] makes the distinction between these two materials a challenging task. Nevertheless, it is possible to observe the orthogonal PCL struts (in red), to which collagen (in

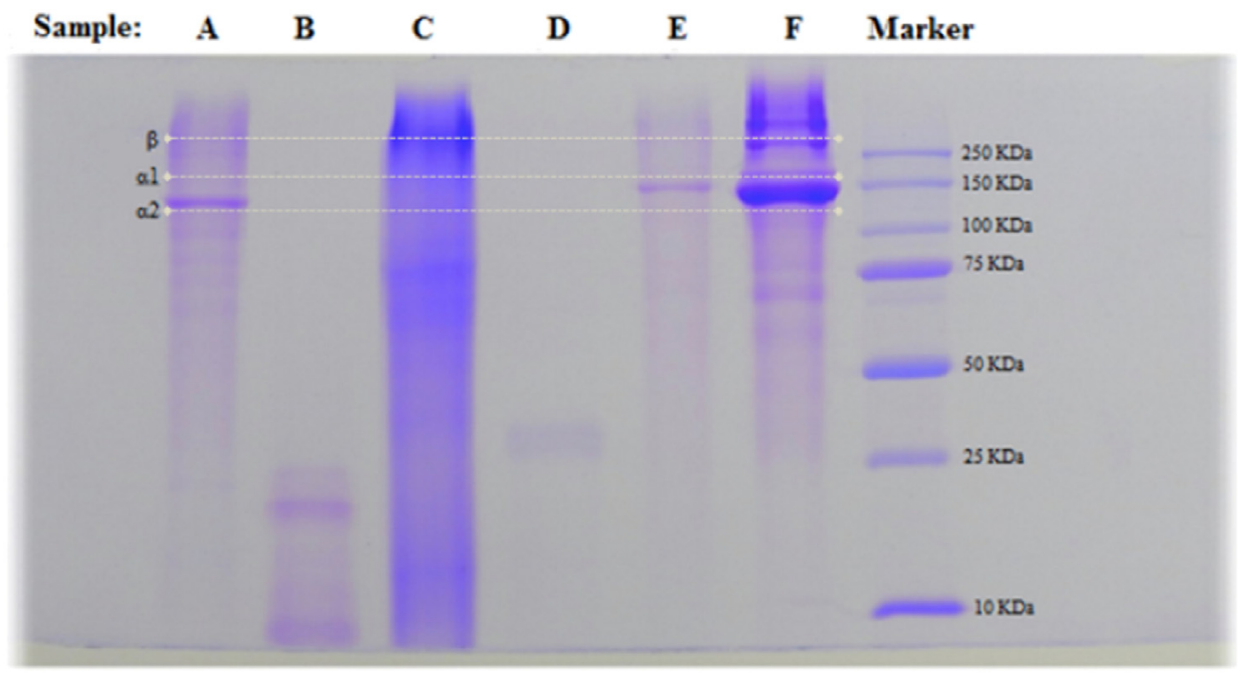

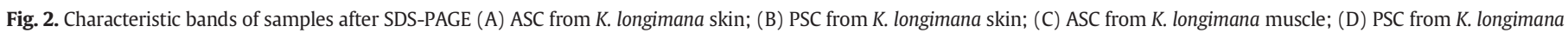
muscle; (E) ASC from I. argentinus skin; (F) PSC from I. argentinus skin). Indication of $\alpha 1, \alpha 2$ and $\beta$ bands was made according to a calf reference. 


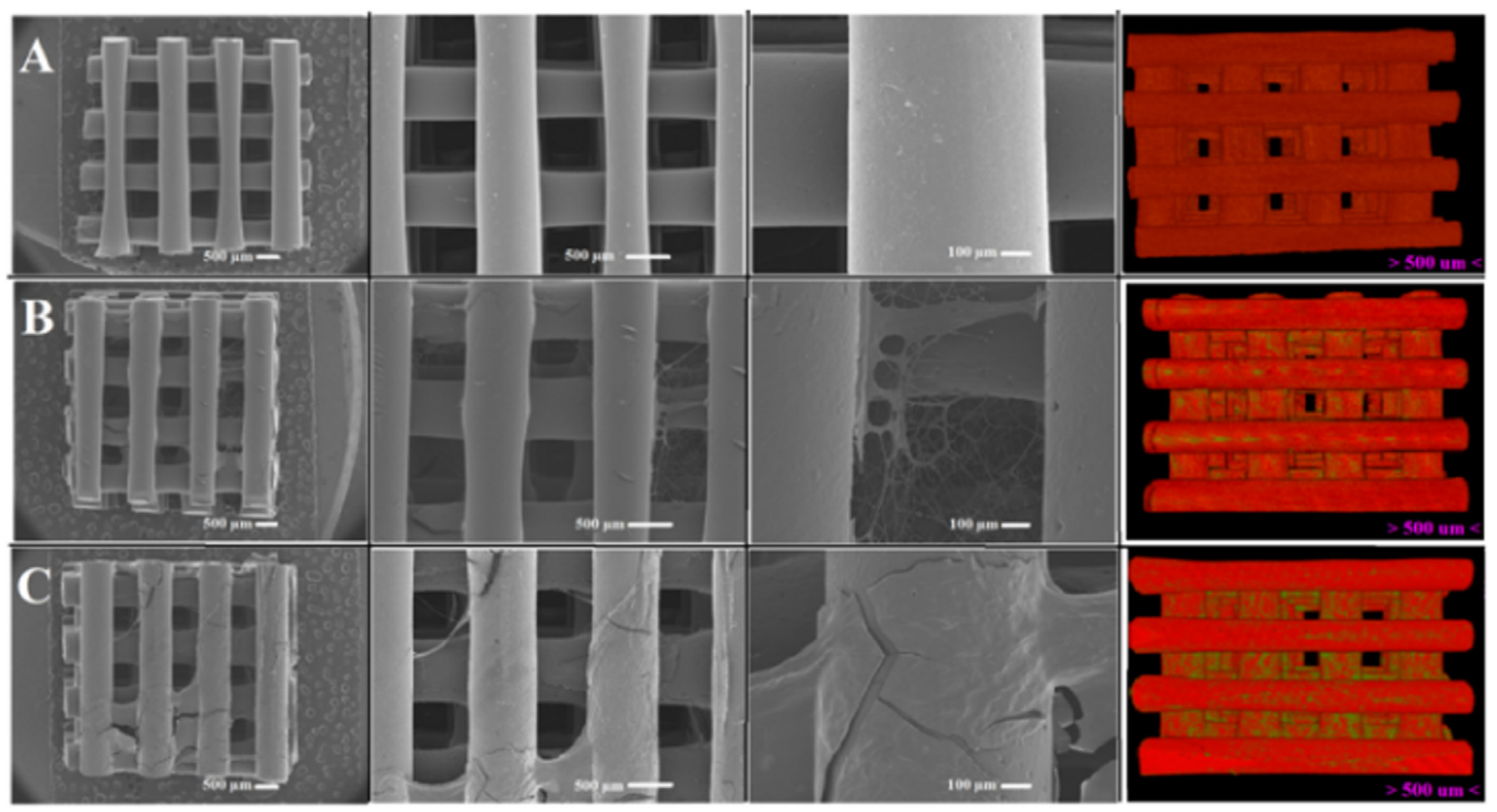

Fig. 3. SEM micrographs and micro-computed tomography images of (A) 3 D printed PCL scaffold; (B) PCL $+0.5 \%$ collagen scaffold; (C) PCL $+1 \%$ collagen scaffold.

green) adhered, forming a microfibrillar structure when using a $0.5 \%$ collagen solution that turned more dense or even into a coating-like structure when the concentration of collagen was increased to $1 \%$. Moreover, the images obtained by micro-CT analysis showed that the collagen structures were uniformly distributed inside the scaffolds.

One of the reasons for the development of hybrid scaffolds is to promote the synergy between the biocompatibility of the natural material with the mechanical properties of the synthetic counterpart. Upon submitting the developed scaffolds to uniaxial compression tests, single collagen structures demonstrated low mechanical properties, as expected, even after collagen crosslinking with genipin: $0.5 \%$ collagen structures presented a Young's modulus of $0.17 \pm 0.04 \mathrm{MPa}$ and $1 \%$ collagen structures exhibited a higher $(\mathrm{p}<0.05)$ Young's modulus of $0.25 \pm 0.05 \mathrm{MPa}$. When analyzing the hybrid scaffolds, the mechanical properties are controlled by the PCL structure, with no statistically significant differences $(\mathrm{p}<0.05)$ being observed between PCL, PCL + $0.5 \%$ collagen or PCL $+1 \%$ collagen scaffolds, with values of compression modulus of around $74 \mathrm{MPa}$.

The water uptake capability of scaffolds gives an important and indirect indication of the hydrophilicity/hydrophobicity of the material. The ability to uptake water influences other major properties and functions of the scaffolds, such as load and drug distribution, cell behavior, among others $[30,61,62]$. Water uptake (swelling) tests were performed only on collagen sponges obtained from freeze drying, since PCL is known to be hydrophobic and its significant mass, compared to the collagen one, would lead to biased results. It was observed that $0.5 \%$ collagen scaffolds could uptake about 3 times its weight in water, while when collagen concentration was increased to $1 \%$, the water uptake capacity was even higher, close to $400 \%$, which shows clearly the hydrophilicity of collagen. These results are in agreement with the ones reported by [63] with 3D printed PCL structures combined with dense chitosan and poly (glutamic acid) hydrogel, showing as well the improved performance of the hybrid scaffold regarding mechanical properties (in comparison to the hydrogel alone) and swelling (in comparison to PCL alone).
To further evaluate the potential of squid collagen for the incorporation on biomaterials for tissue regeneration, the cytotoxicity of the developed hybrid scaffolds was evaluated by assessing the metabolic activity of L929 fibroblast cell line in the presence of the materials. According to the results shown in the graph of Fig. 4, after 1 day in culture the metabolic activity of the cells in the presence of the PCL and hybrid scaffolds is about $80 \%$ of the control, with no significant differences being observed between the different scaffolds. The decrease in metabolic activity observed on the second day of culture for all types of scaffolds was probably due to physical constrains caused by the presence of the scaffold on the well, but it seems to start recovering on the third day, in which no significant differences between scaffolds are observed as well. It was concluded that the hybrid scaffolds are non-cytotoxic.

In addition, the performance of the scaffolds to support cell culture was also briefly addressed by culturing L929 cells onto the structure.

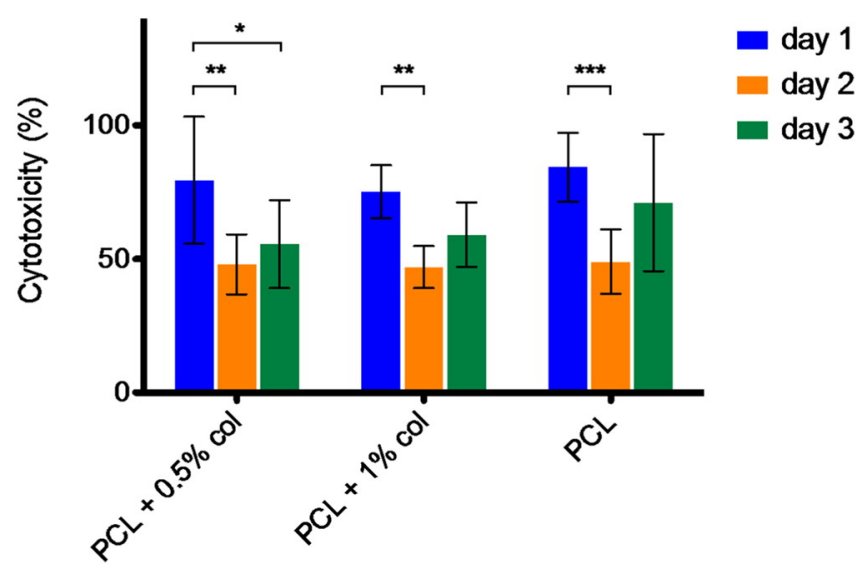

Fig. 4. Cytotoxicity evaluation along 3 days of L929 cells culture in the presence of the PCL and PCL/collagen hybrid scaffolds. * (95\%), ${ }^{* *}$ (99\%) and *** (99.9\%) account for statistically significant differences observed between the metabolic activity of cells at different time points, as determined by two-way ANOVA with Bonferroni post hoc test. 
The representative images of confocal microscopy after up to 3 days in culture, shown in Fig. 5, suggested the cytocompatibility of the materials, with no visible dead cells on the developed structures, both in the absence and presence of collagen modification.

The scaffolds seeded with L929 cells were also observed by scanning electron microscopy (Fig. 6), being possible to observe a significant number of cells adhered on the constructs, particularly in the case of the PCL $+0.5 \%$ collagen scaffold. Cell adhesion is demonstrated by the actin fibers stretching to sustain the cells within the constructs.

During the washings steps, it was observed the partial loss of collagen and cells, affecting negatively the results, from which the efficiency of the adhesion of collagen to the PCL struts needs to be improved. In this regard, other functionalization strategies alternative or complementary to the modification of PCL scaffolds with ethylenediamine will be pursued in future work. Nevertheless, it is possible to conclude that the collagen incorporation into PCL scaffolds is an asset for the cell seeding, taking into account the density of cells present in both conditions ( $\mathrm{PCL}+0.5 \%$ collagen and PCL $+1 \%$ collagen) after $72 \mathrm{~h}$ and the additional anchor points it provides for cell adhesion.

\section{Conclusion}

Collagen has rising in rank as a basic building block of biomedical scientists and engineers, being considered today an integral part of the future of tissue engineering. As alternative to the more common bovine and porcine origins, collagen has been isolated and purified from an Antarctic squid and Sub-Antarctic squid species by using conventional collagen extraction methodologies. The PSC from I. argentinus revealed to be the one obtained not only with higher yield (about 3\%), but also with more preserved structure and with higher purity, exhibiting an amino acid profile and SDS-PAGE pattern consistent with type I collagen.

The combination of PCL 3D printed architectures and collagen microfibrillar structures into hybrid scaffolds gives the possibility to produce new hierarchical biomaterials with potential applications in tissue engineering. In fact, it was possible to overcome the limiting weak mechanical properties of collagen by following this strategy of hybrid scaffolds, with no visible effect on biological performance. With the improvement of the adhesion of collagen to PCL and adding its remarkable biocompatibility and non-immunogenicity, the hybrid scaffolds can be valuable biomaterials for tissue regeneration, with improved mechanical properties and cell seeding efficiency.

\section{Acknowledgements}

This work was partially funded by ERDF through POCTEP Project 0687_NOVOMAR_1_P and by the European Union Seventh Framework Programme for research, technological development and demonstration under grant agreement on ERC-2012-ADG 20120216-321266 (ComplexiTE). The Portuguese Foundation for Science and Technology

\section{PCL}
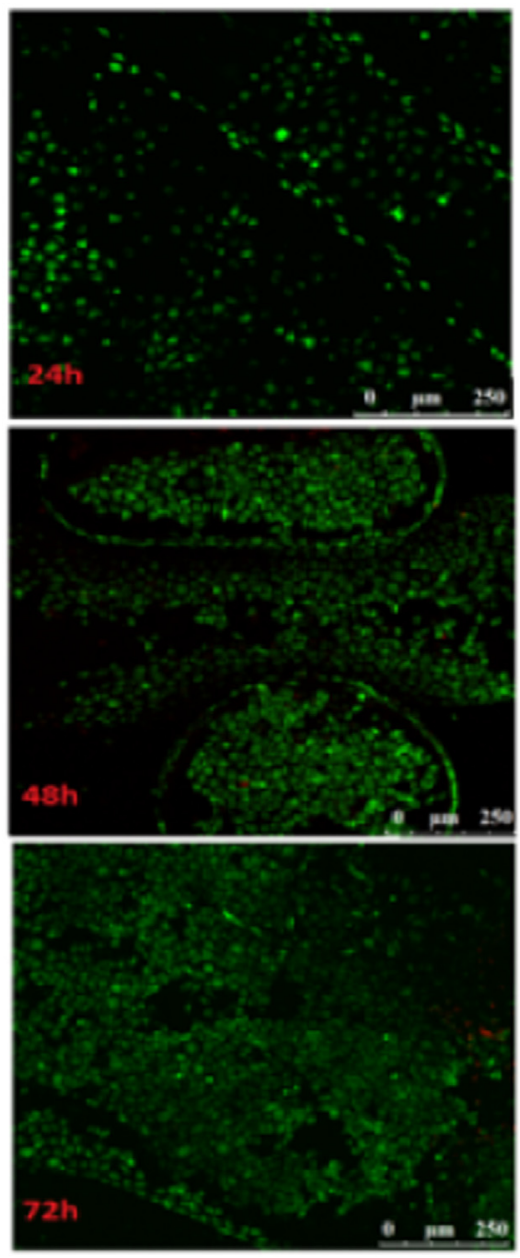

PCL $+0.5 \%$ collagen
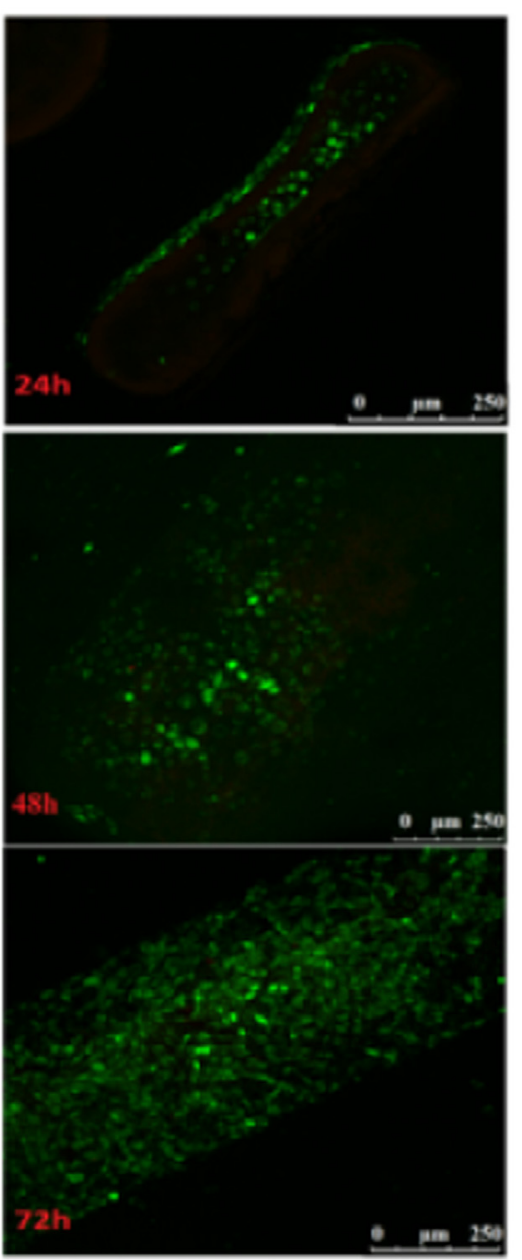

$\mathrm{PCL}+1 \%$ collagen
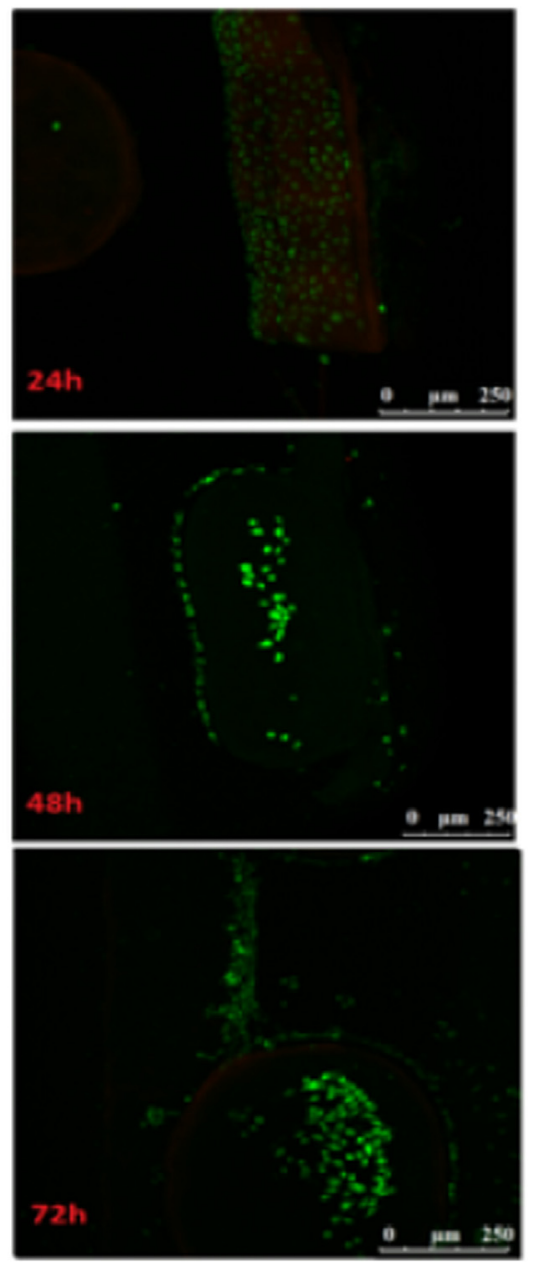

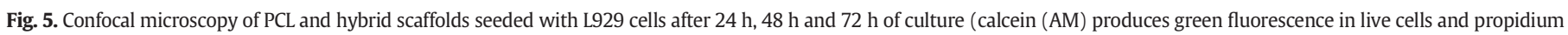
iodide (PI) produces red fluorescence in dead cells). (For interpretation of the references to color in this figure legend, the reader is referred to the web version of this article.) 
PCL
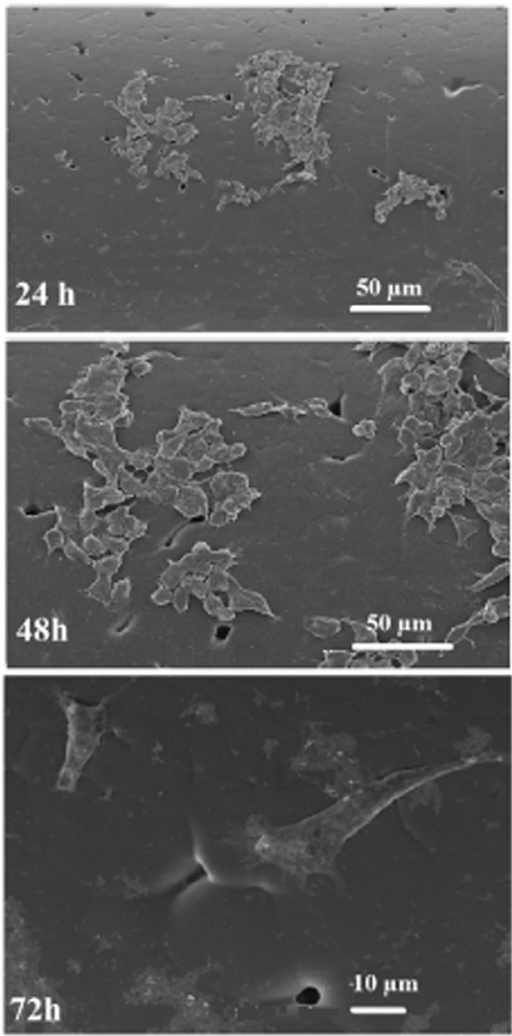

PCL+0.5\% collagen
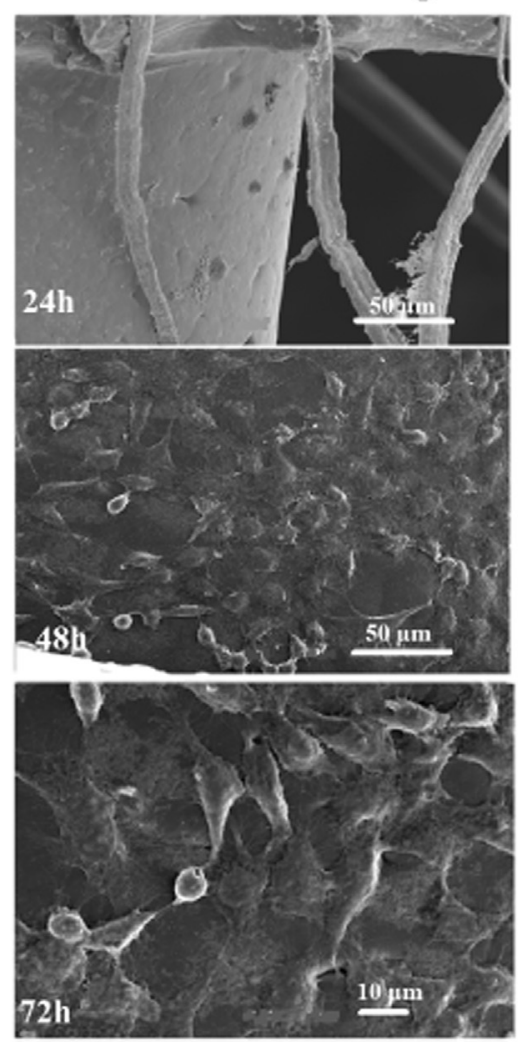

PCL $+1 \%$ collagen
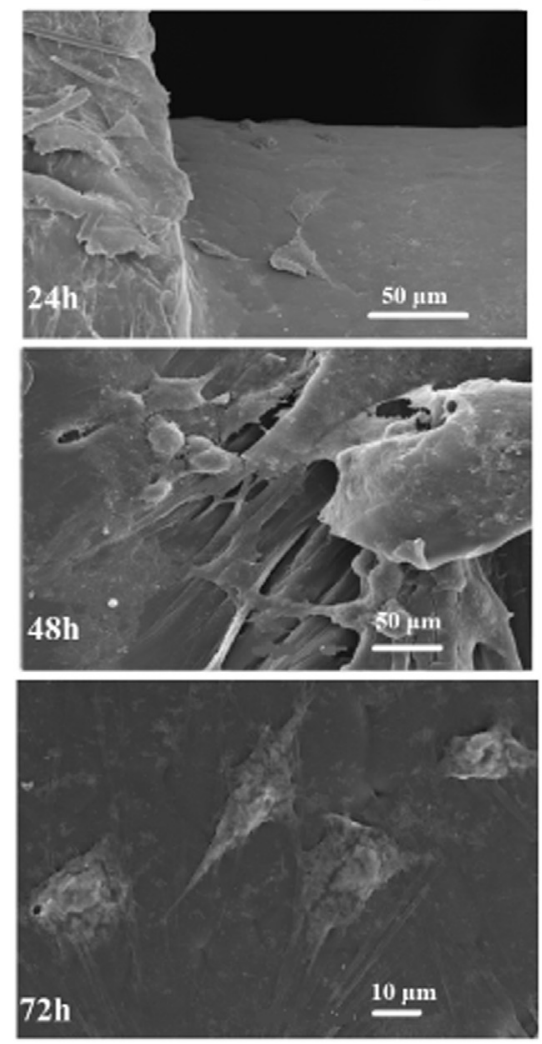

Fig. 6. SEM observation of the produced scaffolds after culturing L929 cells for $24 \mathrm{~h}, 48 \mathrm{~h}$ and $72 \mathrm{~h}$.

(FCT) is also acknowledged for post-doctoral fellowships of JMS (SFRH/ BPD/70230/2010) and RPP (SFRH/BPD/101886/2014), financed by POPH/FSE, and FCT Investigator grant of JX (IF/00616/2013). The authors also want to thank Dr. Julio Maroto (Fundación CETMAR, Spain) for the kind offer of the samples of skins of I. argentinus, to Dr. Dario Fassini for the assistance in SDS-PAGE and to Raphael Canadas for assistance in micro-CT data processing.

\section{References}

[1] A.I. Arkhipkin, Rodhouse PGK, G.J. Pierce, W. Sauer, M. Sakai, L. Allcock, J. Arguelles, J.R. Bower, G. Castillo, L. Ceriola, C.-S. Chen, X. Chen, M. Diaz-Santana, N. Downey, A.F. González, J.G. Amores, C.P. Green, A. Guerra, L.C. Hendrickson, C. Ibáñez, K. Ito, P. Jereb, Y. Kato, O.N. Katugin, M. Kawano, H. Kidokoro, V.V. Kulik, V.V. Laptikhovsky, M.R. Lipinski, B. Liu, L. Mariátegui, W. Marin, A. Medina, K. Miki, K. Miyahara, N. Moltschaniwskyj, H. Moustahfid, J. Nabhitabhata, N. Nanjo, C.M. Nigmatullin, T. Ohtani, G. Pecl, Perez JAA, U. Piatkowski, P. Saikliang, C.A. SalinasZavala, M. Steer, Y. Tian, Y. Ueta, D. Vijai, T. Wakabayashi, T. Yamaguchi, C. Yamashiro, N. Yamashita, L.D. Zeidberg, World squid fisheries, Reviews in Fisheries Science \& Aquaculture 23 (2015) 92-252.

[2] M.R. Bet, G. Goissis, C.A. Lacerda, Characterization of polyanionic collagen prepared by selective hydrolysis of asparagine and glutamine carboxyamide side chains, Biomacromolecules 2 (2001) 1074-1079.

[3] M. Blanco, Valorización de descartes y subprodutos de pintarroja (Scyliorhinus canicula)(PhD thesis) University of Vigo, 2015.

[4] N.O. Chung, M.K. Lee, J. Lee, Mechanism of freeze-drying drug nanosuspensions, Int. J. Pharm. 437 (2012) 42-50.

[5] M.R. Clarke, A review of the systematics and ecology of oceanic squids, Adv. Mar. Biol. 4 (1966) 91-300.

[6] J.L. Drury, D.J. Mooney, Hydrogels for tissue engineering: scaffold design variables and applications, Biomaterials 24 (2003) 4337-4351.

[7] C. Ferrario, L. Leggio, R. Leone, C. Di Benedetto, L. Guidetti, V. Coccèb, M. Ascagnia, F. Bonasoro, C.A.M. La Porta, M.D. Candia, M. Sugni, Marine-derived collagen biomaterials from echinoderm connective tissues, Mar. Environ. Res. (2016) http://dx.doi. org/10.1016/j.marenvres.2016.03.007 (in press).

[8] A.M. Ferreira, P. Gentile, V. Chiono, G. Ciardelli, Collagen for bone tissue regeneration, Acta Biomater. 8 (2012) 3191-3200.

[9] A. Fertala, M.D. Shah, R.A. Hoffman, W.V. Arnold, Designing recombinant collagens for biomedical applications, Current Tissue Engineering 5 (2016) $73-84$.
[10] P. Fratzl, K. Misof, I. Zizak, G. Rapp, H. Amenitsch, S. Bernstorff, Fibrillar structure and mechanical properties of collagen, J. Struct. Biol. 122 (1998) 119-122.

[11] M.C. Gómez-Guillén, B. Giménez, M.E. López-Caballero, M.P. Montero, Functional and bioactive properties of collagen and gelatin from alternative sources: a review, Food Hydrocoll. 25 (2011) 1813-1827.

[12] J.J. Green, J.H. Elisseeff, Mimicking biological functionality with polymers for biomedical applications, Nature 540 (2016) 386-394.

[13] J. Gross, B. Dumsha, N. Glazer, Comparative biochemistry of collagen: some amino acids and carbohydrates, Biochim. Biophys. Acta 30 (1958) 293-297.

[14] M. Haimovici, N.E. Brunetti, P.G. Rodhouse, J. Csirke, R.H. Leta, Illex argentinus, in: P.G. Rodhouse, E.G. Dawe, R.K. O'Dor (Eds.), Squid Recruitment Dynamics. The Genus Illex as a Model, the Commercial Illex Species, and Influences on Variability, FAO Fisheries Technical Paper No. 376 1998, pp. 27-58.

[15] S. Hinderer, S.L. Layland, K. Schenke-Layland, ECM and ECM-like materials - biomaterials for applications in regenerative medicine and cancer therapy, Adv. Drug Deliv. Rev. 97 (2016) 260-269.

[16] D.W. Hutmacher, Scaffolds in tissue engineering bone and cartilage, Biomaterials 21 (2000) 2529-2543.

[17] M.C. Kennicutt, S.L. Chown, J.J. Cassano, D. Liggett, R. Massom, L.S. Peck, S.R. Rintoul, J.W.V. Storey, D.G. Vaughan, T.J. Wilson, W.J. Sutherland, Six priorities for Antarctic science, Nature 512 (2014) 23-25.

[18] P. Kittiphattanabawon, S. Benjakul, W. Visessanguan, T. Nagai, M. Tanaka, Characterization of acid-soluble collagen from skin and bone of bigeye snapper (Priacanthus tayenus), Food Chem. 89 (2005) 363-372.

[19] M.R. Lipinski, K. Turoboyski, The ammonium content in the tissues of selected species of squid (Cephalopoda: Teuthoidea), J. Exp. Mar. Biol. Ecol. 69 (1983) 145-150.

[20] C. Lopes, L.T. Antelo, A. Franco-Uría, A.A. Alonso, R. Pérez-Martín, Valorisation of fish by-products against waste management treatments - comparison of environmental impacts, Waste Manag. 46 (2015) 103-112.

[21] C.C. Lu, R. Williams, Kondakovia longimana Filippova, 1972 (Cephalopoda: Onychoteuthidae) from the Indian Ocean sector of the Southern Ocean, Antarct. Sci. 6 (1994) 231-234.

[22] A.S. Lynnes, P.G. Rodhouse, A big mouthful for predators: the largest recorded specimen of Kondakovia longimana (Cephalopoda: Onychoteuthidae), Bull. Mar. Sci. 71 (2002) 1087-1090.

[23] J.F. Mano, Designing biomaterials for tissue engineering based on the deconstruction of the native cellular environment, Mater. Lett. 141 (2015) 198-202.

[24] J.F. Mano, G.A. Silva, H.S. Azevedo, P.B. Malafaya, R.A. Sousa, S.S. Silva, L.F. Boesel, J.M Oliveira, T.C. Santos, A.P. Marques, N.M. Neves, R.L. Reis, Natural origin biodegradable systems in tissue engineering and regenerative medicine: present status and some moving trends, J. R. Soc. Interface 4 (2007) 999-1030.

[25] J.F. Mano, G. Hungerford, J.L. Gómez-Ribelles, Bioactive poly (L-lactic acid)-chitosan hybrid scaffolds, Mater. Sci. Eng. C 28 (2008) 1356-1365. 
[26] C.A. Miles, A.J. Bailey, Thermal denaturation of collagen revisited, Proceedings of the Indian Academy of Sciences - Chemical Sciences 111 (1999) 71-80.

[27] C.A. Miles, N.C. Avery, V.V. Rodin, A.J. Bailey, The increase in denaturation temperature following cross-linking of collagen is caused by dehydration of the fibres, J. Mol. Biol. 346 (2005) 551-556.

[28] T.J.A. Mommersteeg, J.M. Kauer, R. Huiskes, L. Blankevoort, Method to determine collagen density distributions in fibrous tissues, J. Orthop. Res. 11 (1993) 612-616

[29] J. Moreira-Silva, G.S. Diogo, A.L P. Marques, T.H. Silva, R. Reis, Marine collagen isolation and processing envisaging biomedical applications, in: Neves, Reis (Eds.), Biomaterials from Nature for Advanced Devices and Therapies, John Wiley \& Sons, Inc. New Jersey 2016, pp. 16-36.

[30] L.C. Mozdzen, R. Rodgers, J.M. Banks, R.C. Bailey, B.A. Harley, Increasing the strength and bioactivity of collagen scaffolds using customizable arrays of 3D-printed polymer fibers, Acta Biomater. 33 (2016) 25-33.

[31] T. Nagai, Collagen from diamondback squid (Thysanoteuthis rhombus) outer skin, Zeitschrift für Naturforschung C - A Journal of Biosciences 59 (2004) 271-275.

[32] T. Nagai, E. Yamashita, K. Taniguchi, N. Kanamori, Isolation and characterization of collagen from the outer skin waste material of cuttlefish (Sepia lycidas), Food Chem. 72 (2001) 425-429.

[33] F.J. O'Brien, B.A. Harley, I.V. Yannas, L.J. Gibson, Influence of freezing rate on pore structure in freeze dried collagen-GAG scaffolds, Biomaterials 25 (2004) 1077-1086.

[34] F.J. O'Brien, B.A. Harley, I.V. Yannas, L.J. Gibson, The effect of pore size on cell adhesion in collagen-GAG scaffolds, Biomaterials 26 (2005) 433-441.

[35] S.M. Oliveira, T.H. Silva, R.L. Reis, J.F. Mano, Hierarchical fibrillar scaffolds obtained by non conventional layer-by-layer electrostatic self-assembly, Advanced Healthcare Materials 2 (2013) 422-427.

[36] S.M. Oliveira, R.L. Reis, J.F. Mano, Towards the design of 3D multiscale instructive tissue engineering constructs: current approaches and trends, Biotechnol. Adv. 33 (2015) 842-855

[37] A. Ozcelikkale, B. Han, Thermal destabilization of collagen matrix hierarchical structure by freeze/thaw, PLoS One 11 (2016), e0146660.

[38] R. Parenteau-Bareil, R. Gauvin, F. Berthod, Collagen-based biomaterials for tissue engineering applications, Dent. Mater. 3 (2010) 1863-1887.

[39] R.C. Prestes, Collagen and derivatives: characteristics and applications in meat products, Science, Biology \& Health 15 (2013) 65-74.

[40] D. Puppi, C. Migone, L. Grassi, A. Pirosa, G. Maisetta, G. Batoni, F. Chiellini, Integrated three-dimensional fiber/hydrogel biphasic scaffolds for periodontal bone tissue engineering, Polym. Int. 65 (2016) 631-640.

[41] J.A. Ramshaw, J.A. Werkmeister, V. Glattauer, Collagen-based biomaterials, Biotechnol. Genet. Eng. Rev. 13 (1996) 335-382.

[42] P.G. Rodhouse, H. Griffiths, J.C. Xavier, Southern Ocean squid, in: C. De Broyer, P. Koubbi, H.J. Griffiths, B. Raymond, C.D'. Udekem d'Acoz, A.P. Van de Putte, B. Danis, B. David, S. Grant, J. Gutt, C. Held, G. Hosie, F. Huettmann, A. Post, Y. Ropert-Coudert (Eds.), Biogeographic Atlas of the Southern Ocean, Scientific Committee on Antarctic Research, Cambridge 1998, pp. 284-289.

[43] J. Rosenbloom, M. Harsch, S. Jimenez, Hydroxyproline content determines the denaturation temperature of chick tendon collagen, Arch. Biochem. Biophys. 158 (1973) 478-484.

[44] M.H. Santos, R.M. Silva, V.C. Dumont, J.S. Neves, Extraction and characterization of highly purified collagen from bovine pericardium for potential bioengineering applications, Mater. Sci. Eng. C 33 (2013) 790-800.

[45] J. Seco, G.A. Daneri, F.R. Ceia, R.P. Vieira, S.L. Hill, J.C. Xavier, Distribution of shortfinned squid Illex argentinus (Cephalopoda: Ommastrephidae) inferred from the diets of Southern Ocean albatrosses using stable isotope analyses, J. Mar. Biol. Assoc. U. K. 96 (2016) 1211-1215.

[46] J. Seco, J. Roberts, F.R. Ceia, A. Baeta, J.A. Ramos, V.H. Paiva, J.C. Xavier, Distribution, habitat and trophic ecology of Antarctic squid Kondakovia longimana and Moroteuthis knipovitchi: inferences from predators and stable isotopes, Polar Biol. 39 (2016) 167-175.

[47] F. Shahidi, Maximising the Value of Marine By-products, Woodhead Publishing, 2007 (ISBN 1845690133).

[48] T.H. Silva, J. Moreira-Silva, A.L. Marques, A. Domingues, Y. Bayon, R.L. Reis, Marine origin collagens and its potential applications, Marine Drugs 12 (2014) 5881-5901.

[49] J.C. Silva, A.A. Barros, I.M. Aroso, D. Fassini, T.H. Silva, R.L. Reis, A.R.C. Duarte, Extraction of collagen/gelatin from the marine demosponge Chondrosia reniformis (Nardo, 1847 ) using water acidified with carbon dioxide - process optimization, Ind. Eng. Chem. Res. 55 (2016) 6922-6930.

[50] J.M. Sobral, S.G. Caridade, R.A. Sousa, J.F. Mano, R.L. Reis, Three-dimensional plotted scaffolds with controlled pore size gradients: effect of scaffold geometry on mechanical performance and cell seeding efficiency, Acta Biomater. 7 (2011) 1009-1018.

[51] C. Söderhäll, I. Marenholz, T. Kerscher, F. Rüschendorf, J. Esparza-Gordillo, M. Worm, C. Gruber, G. Mayr, M. Albrecht, K. Rohde, H. Schulz, U. Wahn, N. Hubner, Y.-A. Lee, Variants in a novel epidermal collagen gene (COL29A1) are associated with atopic dermatitis, PLoS Biol. 5 (2007), e242.

[52] E. Song S.Y. Kim, T. Chun, H.J. Byun, Y.M. Lee, Collagen scaffolds derived from a marine source and their biocompatibility, Biomaterials 27 (2006) 2951-2961.

[53] C.G. Sotelo, M. Blanco, P.R. Ariza, R.I. Pérez-Martín, Characterization of collagen from different discarded fish species of the west coast of the Iberian peninsula, Journal of Aquatic Food Product Technology 25 (2016) 388-399.

[54] D. Swatschek, W. Schatton, J. Kellermann, W.E.G. Muller, J. Kreuter, Marine sponge collagen: isolation, characterization and effects on the skin parameters surface-pH, moisture and sebum, Eur. J. Pharm. Biopharm. 53 (2002) 107-113.

[55] S. Sylvie Ricard-Blum, The collagen family, Cold Spring Harb. Perspect. Biol. 3 (2011) a004978.

[56] M.H. Uriarte-Montoya, J.L. Arias-Moscoso, Jumbo squid (Dosidicus gigas) mantle collagen: extraction, characterization, and potential application in the preparation of chitosan-collagen biofilms, Bioresour. Technol. 101 (2010) 4212-4219.

[57] J.C. Xavier, P.G. Rodhouse, P.N. Trathan, A.G. Wood, A geographical information system (GIS) atlas of cephalopod distribution of the Southern Ocean, Antarct. Sci. 11 (1999) 61-62.

[58] J.C. Xavier, A. Brandt, Y. Ropert-Coudert, R. Badhe, J. Gutt, C. Havermans, C. Jones, E.S. Costa, K. Lochte, I.R. Schloss, M.C. Kennicutt II, W.J. Sutherland, Future challenges in Southern Ocean ecology research, Front. Mar. Sci. 3 (2016) 94.

[59] M. Yata, C. Yoshida, S. Fujisawa, S. Mizuta, R. Yoshinaka, Identification and characterization of molecular species of collagen in fish skin, J. Food Sci. 66 (2001) 247-251.

[60] M. Yousefi, F. Ariffin, N. Huda, An alternative source of type I collagen based on byproduct with higher thermal stability, Food Hydrocoll. 63 (2017) 372-382.

[61] M. Zhang, W. Liu, G. Li, Isolation and characterization of collagens from the skin of largefin longbarbel catfish (Mystus macropterus), Food Chem. 115 (2009) 826-831.

[62] J. Zhang, R. Duan, L. Huang, Y. Song, J.M. Regenstein, Characterization of acid-soluble and pepsin-solubilised collagen from jellyfish (Cyanea nozakii Kishinouye), Food Chem. 150 (2014) 22-26.

[63] Q. Zhang, H. Lu, N. Kawazoe, G. Chen, Pore size effect of collagen scaffolds on cartilage regeneration, Acta Biomater. 10 (2014) 2005-2013. 